\title{
Survey of laying hen husbandry in Switzerland
}

\author{
M. HÄNE, B. HUBER-EICHER and E. FRÖHLICH \\ Federal Veterinary Office, Centre for Proper Housing of Poultry and \\ Rabbits, Burgerweg 22, CH 3052 Zollikofen, Switzerland
}

In Switzerland eggs have not been produced in battery cages since January 1992. During the 10 year period from 1981 farmers replaced their battery cages with deep litter, aviary and grid-floor systems and modified cages. However, the cages used to replace the conventional battery cages and most of the gridfloor systems did not fulfil the requirements of the Swiss Welfare Act and they were not permitted to be advertised or sold thereafter. Sixteen years after the ban on battery cages, the Federal Veterinary Office has undertaken a survey to determine how laying hens are kept in Switzerland and how the alternative systems have fared. The survey was carried out on 96 randomly chosen farms with at least 500 hen places to find out more about the housing conditions, management processes, status and performance of hens. The results show that aviaries are very common in Switzerland (65\% of the laying hens) and that the laying performance in these systems is significantly higher than that in gridfloor systems and similar to that in battery cages. Provision of a protected outdoor area is a valuable benefit. To be successful with aviary systems it is necessary for pullets to spend the rearing period under similar housing conditions.

Keywords: Poultry; layers; alternative system; management; aviary system; Switzerland; free range

\section{Introduction}

In Switzerland eggs have not been produced in battery cages since January 1992. The Animal Welfare Act, which came into force in 1981, was the basis for the considerable changes to requirements for housing conditions of laying hens. The Animal Welfare Regulations stipulated a minimum floor area of $800 \mathrm{~cm}^{2}$ or more per bird (depending on the quality of the floor and of the group size), protected and darkened nest boxes and perches for all hens or, as a substitute, a suitably slatted floor which allows the hen to close its claws normally. Since 1981 a large variety of housing systems have been developed as alternatives to battery cages. Because Article 5 of the Animal Welfare Act states that housing systems for farm

(c) World's Poultry Science Association 2000

World's Poultry Science Journal, Vol. 56, March 2000 
animals have to be tested from the welfare point of view, more than 50 alternative housing systems were registered for examination by the Federal Veterinary Office (for more information on the examination procedure see also Fröhlich and Oester, 1988; Steiger, 1988; Wechsler et al., 1997).

Investigations have shown that systems which tried to improve on battery cages, such as 'enriched cages' or 'colony cages', did not fulfil the requirements of the Welfare Act (Federal Veterinary Office, 1987). Although the space per bird was increased and additional equipment was installed, separate areas for feeding, exercise, resting, egg laying and normal behaviour (e.g. preening or dustbathing) were not provided. There was also no space for birds to retreat if they were frightened or if subordinate birds wanted to escape from dominant ones. The lack of stimuli in the hen's environment was evident and panicking, feather pecking and cannibalism were major problems. In order to minimise these problems the light intensity had to be reduced drastically and it was not feasible to run the cages with light intensities of 5 lux or more as required by the Animal Welfare Regulations. Additionally, behavioural problems such as pre-laying pacing and pseudo-dustbathing were observed and the proportion of dirty eggs was high $(6-17 \%)$. In summary, the investigation revealed that the modified battery cages did not meet the Animal Welfare Regulations and consequently they were not authorised by the Federal Veterinary Office (1993a). Similar problems were observed with grid-floor systems (Federal Veterinary Office, 1993b) and many of these did not get authorisation either.

In contrast, aviary systems, i.e. multi-level systems with litter on the floor and manure removal on two or more levels, proved to be a favourable alternative to battery cages (Oester and Fröhlich, 1986; Federal Veterinary Office, 1995) and gained acceptance by poultry farmers. These aviaries also proved to be economically competitive with battery cages. With the provision of tiers and perches at different heights the hens are able to use additional space and it is possible to separate areas for different behavioural functions. With the added possibilities of providing access to a littered and sheltered outdoor area ( $\mathrm{bad}$ weather run' or 'winter garden') and/or a free range area, the birds are able to perform a normal range of behavioural patterns (Swiss Society for the Protection of Animals (STS), 1994; Bessei and Damme, 1998). In aviary systems fewer abnormal and more comfort behaviours may be observed, while productivity remains comparable to battery farming (Tanaka and Hurnik, 1992; Blokhuis and Metz, 1995).

As well as a basic knowledge of egg production, however, more skills and experience are needed to run aviary systems successfully. Additional knowledge of behaviour (e.g. feather pecking), nutrition and animal health is essential (Fröhlich and Oester, 1988; Bessei and Damme, 1998). In aviary systems the welfare of the hens is more susceptible to inadequate supervision and poor management (Appleby and Hughes, 1991). Drawbacks include floor eggs, a high concentration of dust, harmful feather pecking and cannibalism (Blokhuis and Metz, 1995; van Horne, 1996).

In 1997, six years after the last battery cage had been removed, the Federal Veterinary Office wanted to find out more about how laying hens are kept in Switzerland. It commissioned a representative survey aimed at determining housing conditions, management and the health of the hens. The study included all farms with at least 500 places for laying hens, i.e. 742 farms according to the Federal Statistical Office (1995). These farms supply about $75 \%$ of all eggs produced in Switzerland. 


\section{Methods}

In March 1997 the 742 farms were invited to join the survey. In order to obtain a representative sample the letter of invitation was formulated in as neutral a manner as possible. Within two months, $41 \%$ of the farms had replied and $85 \%$ of them (256 farms) agreed to participate. Of these, 105 farms were chosen at random to be included in the study. Between October 1997 and April 1998, 96 of them were visited; the remaining nine were not visited either because they did not have hens at that time or because they had lost interest in the survey. The length of the specially developed questionnaire and the complexity of the topic required a personal visit rather than simply mailing the questionnaire to the farmer. The survey sheet was filled in during an inspection of the hen houses and their environment, and with the help of an interview with the farmer. As a point of reference for information on the management, health and performance of the birds, the eldest flock on the farm and the preceding one were used. Additionally, a pooled sample of excreta (about 20 droppings) was taken from the examined flocks and sent to an accredited laboratory for examination of endoparasites. In the laboratory a suspension of zinc chloride was used (Boch and Supperer, 1992) to detect coccidial oocysts or eggs of worms. The time of the farm visits ranged from 1.5 to 3 hours. To ensure consistent quality of data, all the visits were carried out by the same person.

Because the ages of the examined flocks differed (mean (SD) 59.1 (20.8) weeks), the data concerning performance were not directly comparable. The value of performance is therefore given as the positive or negative difference (in percent) compared with the value on a standard laying curve (eggs per hen-day) for the corresponding age of the flock. This curve is based on an evaluation carried out by the Association of Swiss Poultry Farmers VSGH (1998a) on the performances of 900 commercial flocks. At 72 weeks of age the VSGH standard curve shows 296.3 eggs per hen. This is $4.4 \%$ less than the average performance of caged laying hens in German institutions for breeding selection (Petersen, 1998).

The mortality among the flocks (minimum age 28 weeks) was compared by calculating the average rate per 28 days. The analysis of the data shows no correlation $(r=0.004)$ between the age of the flock and the mortality rate. Data relating performance and mortality could not be collected from all flocks because farmers did not always keep accurate records.

The condition of the plumage was recorded by scoring the appearance of the majority of the hens in a flock. The plumage was scored for damage at five different areas of the body (head/neck, pectoral tract, tail/back, wings, cloaca/ abdominal tract) using a four-point scale where 1 = feathers intact, 2 = feathers bristly and abraded, $3=$ nude spots $<5 \mathrm{~cm}$ in diameter and $4=$ nude spots $>5 \mathrm{~cm}$ in diameter. For the analysis a plumage index (range 5-20) was calculated by adding up the scores from the five body areas.

Generally, means and standard deviations (SDs) were used to describe central tendencies and variabilities of data, and parametric statistics were used to analyse them. In some cases median values with $10 \%$ and $90 \%$ percentiles are given for data with skewed distributions.

\section{Results}

STRUCTURE OF FARMS

In Switzerland the value of production of shelled eggs and egg products amounts to roughly 200 million Swiss francs, a sum which represents $3.6 \%$ of the 
total animal production in 1997 (Schweizerischer Bauernverband, 1998). In addition to selling eggs, most farmers have other sources of income; $79 \%$ of them estimate that they obtain no more than $50 \%$ of their income from the sale of eggs.

The mean (SD) number of birds per farm is 3042 (3600). Today, $59.3 \%$ of the flocks (53.3\% of all laying hens) have access to outdoors. In addition, many of them ( $48.9 \%$ of the flocks, $43.6 \%$ of the hens) have access to a bad weather run and a free range area. Farms where only a free range area is provided with no associated bad weather runs $(4.4 \%$ of the flocks, $2.6 \%$ of the hens) or a bad weather run without a free range area $(6.0 \%$ of the flocks, $7.1 \%$ of the hens) are not very common.

\section{HOUSING CONDITIONS}

Housing systems and equipment. Aviaries are very common in Switzerland with $65.2 \%$ of all laying hens (48.9\% of all flocks) being kept in such systems (Table 1). The four most successful models are Rihs Boleg II (29.2\%), Voletage (24.7\%), Natura 3-tiers $(18.0 \%)$ and Natura 2-tiers (14.6\%). Most large flocks are kept in aviary systems whereas deep litter systems (34.1\% of the flocks) are preferred for smaller flocks.

Almost all hens $(99.1 \%)$ are kept in housing systems with access to litter within the hen house (Table 1). In $86 \%$ of all hen houses the litter area amounts to at least $20 \%$ of the total surface area available to the birds. In this study surfaces were deemed to be available to the birds if there was a height of at least $45 \mathrm{~cm}$ above them, if they were at least $30 \mathrm{~cm}$ wide, and if the slope did not exceed $12 \%$. Straw is usually used as litter (69\%), either alone or in combination with other materials, but wood shavings are also popular $(36 \%)$. Only $14 \%$ of hen houses provide more than $3 \mathrm{~cm}$ of litter at the start of the laying period, but after 2-3 months this rises to $83 \%$. In $21 \%$ of the hen houses the maximum depth of litter during the laying period is more than $10 \mathrm{~cm}$. The depth of litter was never more than $20 \mathrm{~cm}$.

Table 1 Frequency of indoor housing systems for laying hens in Switzerland

\begin{tabular}{|c|c|c|c|}
\hline Name & Description & $\begin{array}{l}\text { Flocks } \\
(\%)\end{array}$ & $\begin{array}{l}\text { Hens } \\
(\%)\end{array}$ \\
\hline Deep litter systems & $\begin{array}{l}\text { System with litter on the floor and droppings pit; } \\
\text { manure removal at one level }\end{array}$ & 34.1 & 18.0 \\
\hline Grid-floor systems & $\begin{array}{l}\text { System without permanently accessible litter area on } \\
\text { the floor }\end{array}$ & 17.0 & 16.8 \\
\hline $\begin{array}{l}\text { (1) without any } \\
\text { litter area }\end{array}$ & System without any litter in the hen house & 3.3 & 0.9 \\
\hline $\begin{array}{l}\text { (2) with separable } \\
\text { litter area }\end{array}$ & System with litter area on the floor, but separable & 1.1 & 0.4 \\
\hline $\begin{array}{l}\text { (3) with raised litter } \\
\text { area }\end{array}$ & $\begin{array}{l}\text { System with raised litter area (central or along the } \\
\text { walls) which can also be separated }\end{array}$ & 12.6 & 15.5 \\
\hline Aviary systems & $\begin{array}{l}\text { Multi-level system with litter on the floor and manure } \\
\text { removal at two or more levels }\end{array}$ & 48.9 & 65.2 \\
\hline
\end{tabular}


Raised perches (at a height of at least $30 \mathrm{~cm}$ above the underlying surface) are provided in $80.2 \%$ of the systems (i.e. in all aviary systems and in $62.7 \%$ of the non-aviary systems). In the remaining systems perches are lower or the floors are made of suitable slats that allow normal closing of the claws when the hen is resting.

The mean (SD) stocking density in deep litter systems is 8.4 (1.4) hens per $\mathrm{m}^{2}$ compared with $8.6(1.7)$ hens per $\mathrm{m}^{2}$ in aviary systems. However, in aviary systems there are additional tiers above the main floor, so the density relative to the floor area rises to $12.5(4.7)$ hens per $\mathrm{m}^{2}$.

There is daylight in $81 \%$ of all poultry houses and $78 \%$ of all hens are kept under natural daylight. The mean (SD) window area amounts to 4(2.2)\% of the floor area. In $13 \%$ of the hen houses light intensity is below that required to read a newspaper (less than about 5 lux). In big houses with several openings leading into a bad weather run or a free range area equalpressure ventilation systems are mainly used. In most of the houses $(95.8 \%)$ the food is provided from chain feeders. Drinking facilities usually consist of nipples $(80.2 \%)$ but cup drinkers $(9.4 \%)$ are also used in some places. Protected and darkened nest boxes are provided in all hen houses. In $15.6 \%$ of the houses there are single nests (surface $<1100 \mathrm{~cm}^{2}$, one nest for five birds), in $69.8 \%$ there are small group nests $\left(1100-6000 \mathrm{~cm}^{2}\right.$, one nest for $11-60$ birds) and in $14.6 \%$ large group nests $\left(>6000 \mathrm{~cm}^{2}\right)$ are used. Most of the single nests $(73 \%)$ have a bowl of plastic as nest ground, whereas corn chaff $(13 \%)$, mats of rubber-burl $(7 \%)$ or coconut fibre $(7 \%)$ are occasionally used. In group nests the nest ground is often made of mats of rubber-burl (46\%), Astroturf (texture of rough fibres of plastic; $30 \%$ ), grids of plastic $(14 \%)$ or corn chaff $(11 \%)$.

Bad weather run. The sheltered and littered bad weather run, which is separated from the free range area by a wall made of wire mesh, usually adjoins the hen house on one or more of its sides. It enables the birds to experience fresh air and an outdoor climate every day, even if the soil of the free range area is too wet to be stepped on or is covered by snow. $54.9 \%$ of flocks have access to a bad weather run. The mean (SD) littered area per hen in the bad weather run is 579 $(274) \mathrm{cm}^{2}$ and $57 \%$ of the bad weather runs have a separate dust bath filled with sand.

Free range area. Of the farmers who keep flocks with access to a free range area, $69.4 \%$ started to do so between 1991 and 1997. 53.3\% of flocks in Switzerland ( $46.2 \%$ of the hens) have access to a pasture with a mean area of pasture per bird of $2.8 \mathrm{~m}^{2}\left(2.4 / 8.1 \mathrm{~m}^{2}\right)$. Correct management of the pasture area is necessary for regenerating damaged and burdened soil (e.g. pasture rotations and separation of certain areas for several weeks) so the area effectively accessible to the birds is smaller and $1.9 \mathrm{~m}^{2}\left(0.5 / 4.8 \mathrm{~m}^{2}\right)$ was calculated to be accessible to the hens at the time of the visit. Although the hens are able to move a mean distance of $80 \mathrm{~m}$ $(50 / 150 \mathrm{~m})$ away from the hen house, they actually only move $50 \mathrm{~m}(20 / 80 \mathrm{~m})$. On most pastures there were parts where the grass had been destroyed, especially around the hen house and in shady places, but these bare areas (18\% of the pastures) seldom amounted to more than $10 \%$ of the free range area.

The average estimated loss of hens to predators in the free range area was 6.7 birds per year per farm, but on $9 \%$ of farms the losses exceeded 20 birds. 
ANIMALS

Hybrids. Pure flocks of white egg laying strains are more common than wholly brown egg laying strains (55.7\% and $33.4 \%$, respectively); with the balance of flocks being mixtures of white and brown egg producers, white egg producers make up $64 \%$ of the total laying hen population surveyed. The most common hybrids are Lohmann White-LSL (27.6\%), Hypex HN (18.1\%), ISA Brown (17.1\%) and Lohmann Brown (8.8\%).

\section{MORTALITY}

The mean (SD) mortality rate of laying hen flocks in Switzerland is $0.69(0.57) \%$ per 28 days. There are significant differences (ANOVA, $\mathrm{DF}_{2,136}, \mathrm{~F}$ ratio $=4.86, p$ $=0.009$ ) in the mortality rates of flocks without access either to a bad weather run or to a free range area $(0.59(0.49) \%, \mathrm{n}=56)$, flocks with access solely to a bad weather run $(0.39(0.20) \%, \mathrm{n}=12)$ and flocks with access to a free range area $(0.83$ $(0.65) \%, \mathrm{n}=71$ ). Using Fisher's method of least significant difference (95\% LSD) to distinguish these values, the mortality rate of flocks with access to a free range area is shown to be significantly higher than that of flocks without any run, as well as that of flocks with only a bad weather run.

The mortality rate of flocks without access to a free range area was examined in the different housing systems. The mortality rate of flocks kept in deep litter systems is $0.75(0.74) \%(\mathbf{n}=11)$, that of flocks kept in grid-floor systems is 0.58 $(0.46) \%(\mathbf{n}=29)$ and that of flocks in aviary systems is $0.45(0.28) \%(n=28)$. Statistical testing does not reveal any significant differences $\left(\mathrm{ANOVA}, \mathrm{DF}_{2,65}, \mathrm{~F}\right.$ ratio $=1.83, p>0.1$ ).

Comparison of the mortality rates of all pure flocks shows that the mortality rate of white egg laying strains $(0.55(0.55) \%, \mathrm{n}=54)$ is significantly lower than that of brown egg laying strains $(0.80(0.59) \%, \mathrm{n}=75 ; t=2.45, p=0.016)$.

Flocks with or without worm eggs in the droppings (see below) at the time of the visit had similar mortality rates $(0.58(0.46) \%, \mathrm{n}=46$ and $0.62(0.66) \%, \mathrm{n}=34$, respectively; $|t|=-0.237, p>0.1)$. The same was true for flocks with or without coccidial oocysts in the droppings $(0.62(0.60) \%, \mathrm{n}=54$ and $0.55(0.46) \%, \mathrm{n}=26$, respectively; $|t|=-0.533, p>0.1)$.

\section{LAYING PERFORMANCE}

There was no significant difference (ANOVA, $\mathrm{DF}_{2,86}, \mathrm{~F}$ ratio $=1.42, p>0.1$ ) between the performances of flocks without any access to a run (mean (SD) 1.6 (5.7) \% above the VSGH standard curve, $\mathrm{n}=31$ ), those with access solely to a bad weather run $(5.1(5.4) \%, \mathrm{n}=8)$ or those with access to a free range area $(2.6(5.0) \%$, $\mathbf{n}=51$ ). A more detailed examination of flocks kept without access to a free range area shows differences between housing systems (ANOVA, $\mathrm{DF}_{2,36}, \mathrm{~F}$ ratio 4.06, $p$ $=0.026)$. Fisher's test for least significant differences (95.0\% LSD) revealed that the performance in aviary systems was significantly higher than that in grid-floor systems $(4.9(4.5) \%, \mathrm{n}=16$ and $-0.5(5.1) \%, \mathrm{n}=15$, respectively), whereas no differences were found between aviaries and deep litter systems $(2.4(7.3) \%, \mathrm{n}=$ 8) and between grid-floor systems and deep litter systems.

No significant difference was found between the performance of pure flocks of white and brown laying strains $(4.2(6.1) \%, \mathrm{n}=28$ and $2.0(4.2) \%, \mathrm{n}=56$, respectively; $|t|=-1.95, p=0.055)$.

There was no difference in performance in flocks with or without worm eggs in the droppings (see below) at the time of the visit $(2.9(4.4) \%, \mathrm{n}=28$ and $3.0(6.6) \%$, 
Table 2 Plumage condition of flocks in different housing systems

\begin{tabular}{|c|c|c|c|}
\hline \multirow[b]{2}{*}{ Housing system } & \multirow{2}{*}{$\begin{array}{l}\text { No. of } \\
\text { flocks }\end{array}$} & \multicolumn{2}{|c|}{ Plumage index } \\
\hline & & Mean & SD \\
\hline Deep litter systems & 16 & $\left.10.6\right|^{*}$ & 4.0 \\
\hline Grid-floor systems & 16 & $13.9\}\left.\right|^{*}$ & 3.2 \\
\hline Aviary systems & 27 & 10.6 & 4.8 \\
\hline
\end{tabular}

*Statistically significant differences $(p<0.05,95 \%$ LSD).

$\mathrm{n}=20$, respectively; $t=0.063, p>0.1)$. The same was true for flocks with or without coccidial oocysts in the droppings $(3.3(4.9) \%, n=31$ and $2.3(6.2) \%, n=$ 17 , respectively; $t=0.636, p>0.1$ ).

\section{CONDITION OF PLUMAGE AND FEATHER PECKING}

In $28.6 \%$ of the visited flocks the majority of hens had nude spots $>5 \mathrm{~cm}$ in diameter (six flocks with induced moulting were excluded from the analysis). In $15.6 \%$ of the flocks the farmers estimated that more than $3 \%$ of hens had bloody injuries caused by pecking, while in $10 \%$ of the flocks the farmer noted once or several times during the laying period a loss of birds from pecking of at least $1 \%$ per month. In $50 \%$ of the flocks examined the farmers observed hens pecking at the plumage of others or, in some rare cases, at themselves; $25.6 \%$ of farmers observed that the birds were pulling out each others' feathers and the same percentage of farmers noticed birds eating feathers that had been pulled out or picked up from the floor.

A comparison of the average plumage indices of hens in different housing systems showed that there are significant differences between flocks kept in gridfloor systems, deep litter systems and aviary systems (ANOVA, DF $5,56, \mathrm{~F}$ ratio = $3.67, p=0.032$ ). Moulted flocks and flocks younger than 50 weeks or older than 70 weeks were excluded to minimise the influence of age (Table 2). Fisher's test for least significant difference revealed that the condition of the plumage of flocks kept in grid-floor systems was significantly worse than that of flocks kept in either deep litter or aviary systems. Provision of access to free range did not significantly affect feathering (plumage index of 11.1 with and 11.9 without access to free range, respectively; $t=0.719, p=0.48, \mathrm{n}_{1}=28, \mathrm{n}_{2}=31$ ).

In Switzerland $59.4 \%$ of the flocks (60.9\% of the hens) are beak trimmed in order to prevent the development of feather pecking. Beak trimming is usually done once during the first 10 days of life but occasionally ( $8.4 \%$ of trimmed hens) at the age of 16-18 weeks when the pullets are moved from the rearing house to the laying house. The usual procedure is to cauterise the tip of the beak by touching it briefly with a hot blade. The use of anti-pecking devices such as vision restricting plastic 'spectacles', rings that prevent complete closure of the mandible or 'bumpers' protruding beyond the beak to prevent destructive pecking are forbidden in Switzerland.

\section{PARASITIC INFECTIONS}

Worm eggs were found in $62 \%$ of droppings samples; $50 \%$ of all flocks were infected with Ascaridia galli, 20\% with Trichostrongylus tenuis, 18\% with Capil- 
laria spp., $7 \%$ with Heterakis gallinarum and $2 \%$ with Raillietina spp. In $49 \%$ of the positive samples there were eggs from two or more different species of worm. The infection rate was significantly higher in flocks having access to a free range area $(75 \%)$ than in those without $\left(43 \% ; \chi_{1}^{2}=10.40, p=0.001\right)$. Oocysts of Eimeria spp. were found in $67 \%$ of all samples. The infection rate of Eimeria was significantly higher in flocks having access to a free range area $(73 \%)$ than in those without $\left(43 \% ; \chi^{2}{ }_{1}=9.20, p=0.002\right)$. During the laying period of the preceding flock, $77 \%$ of the farmers identified red mites (Dermanyssus gallinae) in the poultry house.

\section{Discussion}

With the support of political measures and the acceptance of consumers, commercial egg production can be run successfully without the use of battery cages in Switzerland. In 1991, the year egg production in battery cages was abolished, 630 million eggs were produced and this number had increased to 663 million in 1997. During this time the percentage of home produced shelled eggs increased from $62 \%$ to $73 \%$ of total shelled eggs consumed (Association of Swiss Poultry Farmers VSGH, 1998b).

The majority of hens are kept either in aviary or deep litter systems. These are often combined with access to an outdoor area which usually includes a bad weather run as well as a free range area. We found that the mortality and performance of hens kept in aviary systems without access to a free range area was similar to that reported for hens kept for breeding selection tests in battery cages in Germany where, on average, $0.38 \%$ losses per 28 days and 309.9 eggs per hen-day (day 141 to day 504) were found (Petersen, 1998). These findings are similar to those of Blokhuis and Metz (1995) who reported that egg production per hen in aviaries can equal that in battery cages. According to their report, this also holds true for the mortality rate, but only when the hens have had their beaks trimmed. Appleby and Hughes (1991) stated that there was no evidence to show that results were better in cages or in alternative systems, especially when the fact that more eggs are likely to remain uncollected in alternative systems is taken into account. Our results show that flocks kept in grid-floor systems lay significantly fewer eggs than flocks kept in aviary systems, whereas no difference was found between flocks kept in aviary and deep litter systems.

Flocks with access solely to a bad weather run have fewer losses than flocks with access to a free range area. In addition to the low mortality rate, access to a bad weather run also has other advantages. Reduced stocking density with some of the birds outside enables weaker or pursued hens to withdraw and to get a better opportunity to feed and it enables the staff to check hens and equipment more easily. Furthermore, production of dust in the hen house decreases and air quality is improved.

Whereas the mortality rate of flocks with access solely to a bad weather run is low, that of flocks with access to a free range area is high. There have been several reports where predators, parasites, infection and unfavourable weather conditions have been discussed as possible causes for the increased losses (e.g. Laing, 1988; Tüller, 1996), but evaluating the complex interactions between environmental factors, infection factors and stress factors in the field is difficult. According to the farmers, losses of hens from predation are not numerous, although problems with local hawks do occur. Flocks with access to a free range area are more likely 
to have coccidial oocysts and worm eggs than flocks without. However, the presence of worm eggs or Eimeria oocysts does not correspond to a higher mortality rate or a lower laying performance. Similarly, Permin et al. (1998) found no significant differences in egg production between hens infected with Ascaridia and those not infected.

There are still a number of problems to be solved in the management of free range areas. Actual experiences of poultry farmers have shown that access to the free range area has to be restricted because of damage to the soil near the hen house and in shady places. High parasitic contamination near the hen house, as found by Bray and Lancaster (1992), may be a risk to the health of the hens and we therefore support the use of paddock rotation. The distribution of hens on the grass could be improved by offering dispersed shadow facilities in order to reduce the risk of the accumulation of nitrogen and phosphate in highly frequented places (Meierhans and Menzi, 1995). When giving advice on the management of free range areas, one should keep in mind that $90 \%$ of the inspected flocks only use the pastures to a maximal distance of $80 \mathrm{~m}$ from the hen house, and that some parts of the pasture generally have to be separated for recovering the soil.

In alternative housing systems with access to a bad weather run or a free range area the environment is not strictly controlled and more attention has to be paid to the quality of the plumage. Partially defeathered birds, especially when exposed to lower temperatures, experience increased heat loss associated with a decrease in feed efficiency (Deschutter and Leeson, 1986; Elliot, 1996). An analysis of the influence of the housing system on the plumage condition revealed that flocks kept in grid-floor systems have significantly worse plumage than those kept in deep litter or aviary systems. As feather pecking is regarded a major factor in feather loss (Hughes, 1985; Elliot, 1996), it can be concluded that there are more problems with feather pecking in grid-floor systems (i.e. systems without a permanent accessible litter area on the floor). This is supported by Blokhuis (1986) and Huber-Eicher and Wechsler (1998) who found that provision of an appropriate foraging material increases foraging behaviour and decreases the development of feather pecking. Thus, hens should be raised and kept with unrestricted access to a suitable litter substrate in order to reduce the development of feather pecking, to increase the quality of the plumage and, as a consequence, to reduce economical losses through decreased feed efficiency.

Considering all these points and the fact that the management of litter and daylight in the hen house requires additional skills, it is obvious that the staff have to be well educated. Furthermore, the hens have to be adapted to these more complex housing conditions. Hens that are going to be kept in aviaries, for example, should also be reared in aviaries so that the use of the third dimension and the equipment of aviary systems is improved when the hens are introduced into their laying facilities (Fröhlich, 1982; Gunnarsson et al., 1999; Huber-Eicher, 1999).

\section{Acknowledgements}

We are grateful to the Federal Veterinary Office of Switzerland for the financial support of the research project (No. 2.97.1), to Laurent Audigé for his valuable comments on the layout of the study and to Amanda Barnard for help with the translation. 


\section{References}

APPLEBY, M.C. and HUGHES, B.O. (1991) Welfare of laying hens in cages and alternative systems: environmental, physical and behavioural aspects. World's Poultry Science Journal 47: 109-128

ASSOCIATION OF SWISS POULTRY FARMERS VSGH (1998a) Tätigkeitsbericht 1997. Verband Schweizerischer Geflügelhalter VSGH, Bern, Switzerland

ASSOCIATION OF SWISS POULTRY FARMERS VSGH (1998b) Jahresbericht 1997. Verband Schweizerischer Geflügelhalter VSGH, Bern, Switzerland

BESSEI, W. and DAMME, K. (1998) Neue Verfahren für die Legehennenhaltung. In: KTBL-Schrift 378. Kuratorium für Technik und Bauwesen in der Landwirtschaft e.V. (KTBL), Darmstadt, Germany

BLOKHUIS, H.J. (1986) Feather-pecking in poultry: its relation with ground-pecking. Applied Animal Behaviour Science 16: 63-67

BLOKHUIS, H.J. and METZ, J.H.M. (1995) Aviary Housing for Laying Hens. ID-DLO Institute for Animal Science and Health, Lelystad, The Netherlands

BOCH, J. and SUPPERER, R. (1992) Veterinärmedizinische Parasitologie. Verlag Paul Parey, Berlin und Hamburg, 4. Auflage, pp. 54-56

BRAY, T.S. and LANCASTER, M.B. (1992) The parasitic status of land used by free range hens. British Poultry Science 33: 1119-1124

DESCHUTTER, A. and LEESON, S. (1986) Feather growth and development. World's Poultry Science Journal 54: 259-267

ELLIOT, M. (1996) Factors influencing feathering. Poultry International November: 80-81

FEDERAL VETERINARY OFFICE (1987) Berichte über die praktische Prüfung auf Tiergerechtheit der Legehennenkäfige Oekonom 165 und Scharbo $162 \mathrm{~V}$. Bundesamt für Veterinärwesen, Liebefeld-Bern, Switzerland

FEDERAL VETERINARY OFFICE (1993a) Kurzbeschreibung der für den Verkauf nicht zugelassenen Haltungssysteme für Legehennen. Information Tierschutz 800.107.06, Bundesamt für Veterinärwesen, Liebefeld-Bern, Switzerland

FEDERAL VETERINARY OFFICE (1993b) Bericht über die praktische Prüfung der Schräggitterhaltungssysteme auf Tiergerechtheit. Bundesamt für Veterinärwesen, Liebefeld-Bern, Switzerland

FEDERAL VETERINARY OFFICE (1995) Kurzbeschreibung der in der Schweiz verfügbaren, serienmässig hergestellten Haltungssysteme für Legehennen. Information Tierschutz 800.107.04, Bundesamt für Veterinärwesen, Liebefeld-Bern, Switzerland

FRÖHLICH, E. (1982) Zum Einfluss der Aufzuchtbedingungen auf das Verhalten von Hennen. In: KTBL-Schrift 291, Kuratorium für Technik und Bawwesen in der Landwirtschaft e.V. (KTBL), Darmstadt, Germany

FRÖHLICH, E. and OESTER, H. (1988) Anwendung ethologischer Erkenntnisse bei der Prüfung der Tiergerechtheit von Stalleinrichtungen und Haltungssystemen für Legehennen. In: KTBL-Schrift 336, Kuratorium für Technik und Bauwesen in der Landwirtschaft e.V. (KTBL), Darmstadt, Germany

GUNNARSSON, S., KEELING, L.J. and SVEDBERG, J. (1999) Effect of rearing factors on the prevalence of mislaid eggs, cloacal cannibalism and feather pecking in commercial flocks of loose housed laying hens. British Poultry Science 40: 12-18

HUBER-EICHER, B. (1999) A survey of layer-type pullet rearing in Switzerland. World's Poultry Science Journal 55: $83-92$

HUBER-EICHER, B. and WECHSLER, B. (1998) The effect of quality and availability of foraging materials on feather pecking in laying hen chicks. Animal Behaviour 55: 861-873

HUGHES, B.O. (1985) Feather loss as a problem: how does it occur? In: Proceedings of Second European Symposium on Poultry Welfare, WPSA, Celle, pp. 177-188

LAING, P.M. (1988) Diseases of free range birds. World's Poultry Science foumal 44: 72-74

MEIERHANS, D. and MENZI, H. (1995) Phosphatbelastung ist problematisch. Schweizerische Geflügelzeitung 8: 6-13

OESTER, H. and FRÖHLICH, E. (1986) Die Beurteilung der Tiergerechtheit der neuen Haltungssysteme für Legehennen im Rahmen der Tierschutzgesetzgebung. Schweizer Archiv für Tierheilkunde 128: 521-534

PERMIN, A., NANSEN, P., BISGAARD, M. and FRANDSEN, F. (1998) Ascaridia galli infections in free range layers fed on diets with different protein contents. British Poultry Science 39: $441-445$

PETERSEN, J. (1998) Zusammengefasste Leistungsprüfungsergebnisse 1995/96'. In: Jahrbuch für Geflügelwirtschaft 1998. Verlag Eugen Ulmer, Stuttgart, Germany

SCHWEIZERISCHER BAUERNVERBAND (1998) Statistische Erhebungen und Schätzungen 1997. Schweizerischer Bauernverband, Brugg, Switzerland 
STEIGER, A. (1988) Swiss animal welfare legislation and the examination of housing systems. In: Proceedings of the Fourth European Conference on the Protection of Farm Animals, Brussels, Belgium, pp. 89-92

SWISS SOCIETY FOR THE PROTECTION OF ANIMALS (STS) (1994) Laying hens: 12 years of Experience with New Husbandry Systems in Switzerland. Kümmerli \& Frey AG, Bern, Switzerland

TANAKA, F. and HURNIK, J.F. (1992) Comparison of behaviour and performance of laying hens housed in battery cages and an aviary. Poultry Science 71: 235-243

TÜLLER, R. (1996) Haltungssysteme für Legehennen: Konventionell oder alternativ - Kompromisse sind unvermeidbar. DGS Magazin Woche 27/96: 20-25

VAN HORNE, P.L. (1996) Production and economic results of commercial flocks with white layers in aviary systems and battery cages. British Poultry Science 37: 255-261

WECHSLER, B., FRÖHLICH, E., OESTER, H., OSWALD, T., TROXLER, J., WEBER, R. and SCHMID, H. (1997) The contribution of applied ethology in judging animal welfare in farm animal housing. Applied Animal Behaviour Science 53: 33-43 